\title{
Metallic Phthalocyanines: impact of the film deposition method on its supramolecular arrangement and sensor performance
}

\author{
MATEUS D. MAXIMINO, CIBELY S. MARTIN, MATHEUS S. PEREIRA and PRISCILA ALÉSSIO \\ São Paulo State University (UNESP), School of Technology and Applied Sciences, \\ 305 Roberto Simonsen St, 19060-900 Presidente Prudente, SP, Brazil \\ Manuscript received on November 13, 2018; accepted for publication on February 5, 2019
}

\begin{abstract}
How to cite: MAXIMINO MD, MARTIN CS, PEREIRA MS AND ALÉSSIO P. 2019. Metallic Phthalocyanines: impact of the film deposition method on its supramolecular arrangement and sensor performance. An Acad Bras Cienc 91: e20181201. DOI 10.1590/0001-3765201920181201.
\end{abstract}

\begin{abstract}
This short review gives a concise overview of the impact of deposition methods on the supramolecular arrangement of metallic phthalocyanine films and their applications. Primarily, an introduction about the possible phthalocyanine molecular structures and derivatives obtained from modification on the phthalocyanine rings was presented. The possibility of perfecting/improving the supramolecular arrangement of metallic phthalocyanine (MPcs) films by using different deposition techniques such as Langmuir-Blodgett (LB), Langmuir-Schaefer (LS), Layer-by-Layer (LbL), physical vapor deposition (PVD) and electrodeposition was discussed in further details. Herein, we highlighted some techniques used on the characterization of supramolecular arrangement (morphology, optical properties, and molecular organization), including the impact on sensing applications. The main scope of this short review is focused on the advances made in this research field in the last five years.
\end{abstract}

Key words: film deposition methods, metallic phthalocyanines, sensing applications, supramolecular arrangement.

\section{INTRODUCTION}

Phthalocyanines (Pcs) are a class of compound that display many applications, mostly related to dyes and inks due to its intense color (Hakeim et al. 2015). Four isoindole groups linked by nitrogen atoms compose its structure (Figure 1a). Moreover, the Pcs features their metallic version known as metallophathalocyanines (MPcs), allowing around 70 different metals to be attached to the center of its structure (Figure 1b). For example,

Correspondence to: Priscila Aléssio

E-mail: priscila.alessio@unesp.br,

prialessio@gmail.com

ORCid: https://orcid.org/0000-0002-1345-0540 the incorporation of copper ion results in a $\mathrm{CuPc}$. The additions of peripheral groups along the Pc structure alter some their properties. For instance, the inclusion of sulfonic groups (Figure 1c) in its structure enhances the solubility in water, thus creating many other possibilities of applications (Furini et al. 2013, Gomes et al. 2015, Xu et al. 2016). The substitution of hydrogen by halogen atoms are a new approach to synthesis and application of MPc (Figure 1d) (Alessio et al. 2014, Basova et al. 2013, 2018). In addition, varieties of metallo-bis-phthalocyanines (double-decker, $\mathrm{MPc}_{2}$ - Figure 1e) have been applied to the fabrication of thin films towards sensing application, due 
to electrocatalytic properties and the specific electronic structure (Alessio et al. 2014, Gay Martín et al. 2012, Medina-Plaza et al. 2014a, RodriguezMéndez et al. 2009). In double-decker structure is common the incorporation of rare earth metals, mainly elements of the lanthanide family. The latter occurs because the availability of electrons in $4 f$ orbital gives possibilities of hybridization and complexes creation with coordination number 8 . (Weiss and Fischer 2003).

Having such a variety of compounds produce several distinguishable attributes such as thermal and chemical stability, and prominent optical and electrical properties, including semiconducting behavior, which make it well likely to be used in several devices (Fleetham et al. 2014, Takeda et al. 2013). Most of the Pcs application is related to dyes and pigments, and considering the relatively inexpensive cost to synthesize in large scale, the
MPcs have been widely used in laboratories and companies.

The optical versatility of the Pcs translates directly on their recently optical applications such as photovoltaic cells, photoreceptors, and photodynamic therapy. Due to properties of the chromophore such as an efficient light absorption in the red visible wavelengths and photoconductive characteristics (Andzelm et al. 2007). These attributes are an outcome of the conjugated macrocycle with a network of $\pi$-electrons, giving the Pcs their high electron polarizability and fast nonlinear response to electromagnetic fields (Sheehy and DiMauro 1996).

The position that the molecules assume after the deposition of a thin film affects some properties, such effect is known as "supramolecular arrangement". Specially MPcs have attracted considerable interest in the development of devices (a) $\mathrm{Pc}$

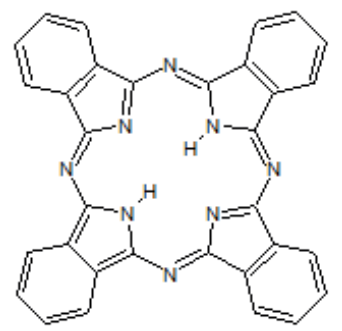

$\mathrm{Na}^{*}$

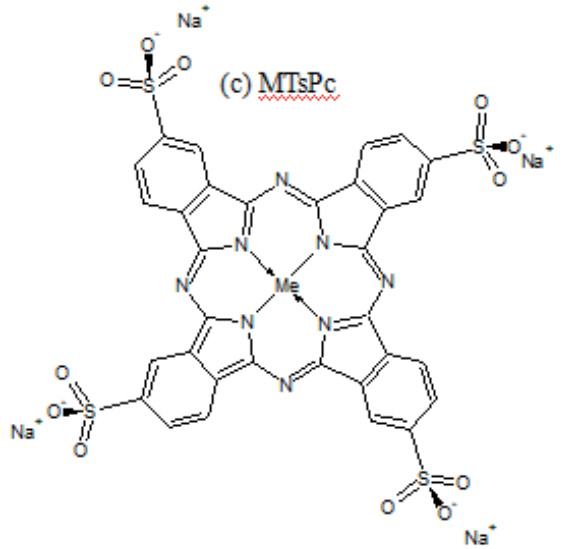

(b) $\mathrm{MPc}$

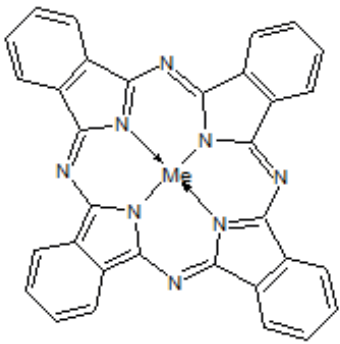

(d) $\mathrm{MPcX}_{16}$

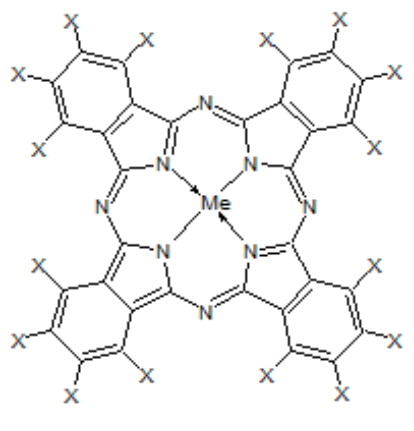

(e) $\mathrm{MPc}_{2}$
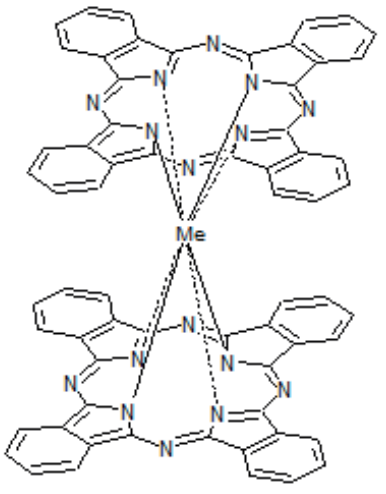

Figure 1 - Chemical structure of (a) phthalocyanine (Pc), (b) metallophthalocyanine (MPc), (c) phthalocyanine with side groups $\left(\mathrm{SO}_{3}^{-}\right)$attached its structure $(\mathrm{MTsPc}),(\mathbf{d})$ phthalocyanine with halogen substitution $\left(\mathrm{MPcX}_{16}, \mathrm{X}=\mathrm{Cl}\right.$ or $\mathrm{F})$, and (e) double-decker phthalocyanine ( $\left.\mathrm{MPc}_{2}\right)$. 
and applications that take advantage on such characteristic of organized thin films (Camacho et al. 2014, Martin et al. 2018, Pavinatto et al. 2011, Rubira et al. 2017). In this case, the properties are directly related to the supramolecular arrangement, which can be tuned by the deposition technique (Martin et al. 2018, Volpati et al. 2008), MPc molecule used (Del Caño et al. 2005, Usol'tseva et al. 2014) as well as thermal treatment (Roy et al. 2014). In this point of view, this short review discussed further in details how different techniques of film deposition such as Langmuir-Blodgett (LB), Langmuir-Schaefer (LS), Layer-by-Layer (LbL), and electrodeposition affects the supramolecular arrangement and influence its performance in sensor applications. Highlighting some of the most relevant works developed throughout the last five years.

\section{TECHNIQUE OF DEPOSITION}

The deposition methods applied to the formation of the MPc and MTsPc films can tune the supramolecular arrangement, which contributes to the development of technological devices. Here we describe techniques used to the fabrication of thin films from MPc derivatives with the ability to tune the supramolecular arrangement as well as the effect on sensing applications.

\section{LANGMUIR-BLODGETT AND LANGMUIR- SCHAEFER}

The Langmuir films consist of a nanostructured monomolecular layer of molecules, generally amphiphilic, floating on water surface. The technique provides a packed and uniform interface, due to the characteristics of the molecules spread into the water surface. The way of transferring the monolayer to a substrate generates different arrangements. The deposition technique known as Langmuir-Blodgett (LB) consists in the vertical transposition of the film. Thus, the substrate is immersed or emerged from the surface perpendicularly (Blodgett 1935), usually performed with speed controlled dipper, providing different arrangements depending on how the molecule deposits (Petty 1996). The Langmuir-Schaefer (LS) technique is a simpler method, which consists of the transposition of the monolayer just by touching the surface horizontally (Langmuir and Schaefer 1937, 1938). Such a procedure is usually performed manually.

LB and LS techniques are often used to MPc with high solubility in volatile organic solvents like chloroform. The last articles have shown in general, the LB and LS films can provide similar supramolecular arrangement to MPc films due to the previous formation at the air/water interface from Langmuir films (Alessio et al. 2014, Martin et al. 2018, Rubira et al. 2017, Volpati et al. 2008). Moreover, the supramolecular arrangement of LB films from FePc can be tuned by the organic solvent used in the solution preparation (Rubira et al. 2017). The solvent contribution is mainly due to the aggregation behavior of FePc, which is strongly dependent on the organic solvent used, revealed by using UV-VIS absorption spectroscopy. In general, the MPcs are the molecules responsible for the absorbance in visible spectral range. The MPcs present two characteristic bands both ascribed to $\pi-\pi$ transitions ( $\mathrm{S}$ and Q-bands) (Wöhrle 1993) The S-band are observed at a lower wavelength and assigned to $\pi-\pi$ transitions in the Pc macrocycle ring. The Q-band is observed at a higher wavelength and can be assigned to $\pi-\pi$ transitions of monomers and dimmers (Furini et al. 2013, Martin et al. 2018, Medina-Plaza et al. 2014b, Wöhrle 1993). Thus, levels of aggregation can be monitored using the absorption of Q-band by observing shifts in the spectra. In this aspect, similar levels of aggregates were obtained using the solvents $\mathrm{CHCl}_{3}, \mathrm{CH}_{2} \mathrm{Cl}_{2}$, and tetrahydrofuran (THF), while in dimethylformamide (DMF) the $\mathrm{FePc}$ aggregation is lower (Rubira et al. 2017). 
However, after one week the DMF also promotes a high level of aggregation in solution. Besides, the Q-band from UV-VIS spectra allied with AFM images can provide information about the aggregation level of MPc (Martin et al. 2018, Medina-Plaza et al. 2014b). In work reported by Rubira, R.J.G. et al. (Rubira et al. 2017) the FePc LB films using DMF presented more homogeneous surface morphology with lower roughness than FePc LB film using $\mathrm{CH}_{2} \mathrm{Cl}_{2}$, as shown in the atomic force microscopy (AFM) images (Figure 2).

Using morphological information (AFM and/or optical images) combined with chemical information from Raman mapping, the homogeneity, as well as aggregation levels of MPcs films can be determined (Furini et al. 2013, Medina-Plaza et al. 2014b, Rubira et al. 2017). Since Raman spectra are collected point-by-point, the intensity or area of a specific band (more intense band) varies according to the homogeneity of the film surface. Thus, Rubira, R.J.G. (Rubira et al. 2017) reports a mapping of the high-intensity band at $1517 \mathrm{~cm}^{-1}$ ascribed to $\mathrm{CNC}$ stretching, and $\mathrm{C}-\mathrm{H}$ deformation of FePc LB films, showing that the aggregation depends on the solvent used to the formation of LB films. The dependence of solvents on the FePc LB films sensing application was also observed. The $\mathrm{FePc} / \mathrm{CH}_{2} \mathrm{Cl}_{2}$ and $\mathrm{FePc} / \mathrm{DMF}$ LB films were applied as an electronic sensor to detection of atrazine (an herbicide) (Rubira et al. 2017). The sensing units composed of LB film fabricated using FePc in fresh DMF was similar to the aged DMF, but differently than LB film with $\mathrm{FePc}$ in $\mathrm{CH}_{2} \mathrm{C}_{2}$ (Rubira et al. 2017). The results from IDMAP projection (Interact Document Map) shows how different the impedance spectra were, indicating the effect of the supramolecular arrangement of this films on sensing response (Figure 3). Besides, the FePc LB films (independent of solvent) revealed the high sensitivity of the sensor array detecting atrazine, in a concentration lower than $10^{-10} \mathrm{~mol} / \mathrm{L}$.

In general, the MPc films presents molecular aggregates due to the tendency of phthalocyanines to aggregate themselves in solution, which can be transferred to the substrate surface during the film deposition (Martin et al. 2018, Rubira et al. 2017). This tendency of self-aggregation in solution affects the Langmuir films changing the extrapolated area at the $\Pi$-A isotherms to bigger values of the mean molecular area and consequently the supramolecular arrangement of LB and LS films (Martin et al. 2018, Rubira et al. 2017, Volpati et al. 2008). Thus, to decrease the aggregation level as well as increase the flexibility or stability of the MPc monolayers, amphiphilic molecules can be mixed in solution or co-spread at air/water interface. Thus, the LB and LS techniques can also be used to the formation of mixed Langmuir films composed by two or more compounds which can be mixed at the solution or co-deposited at air/
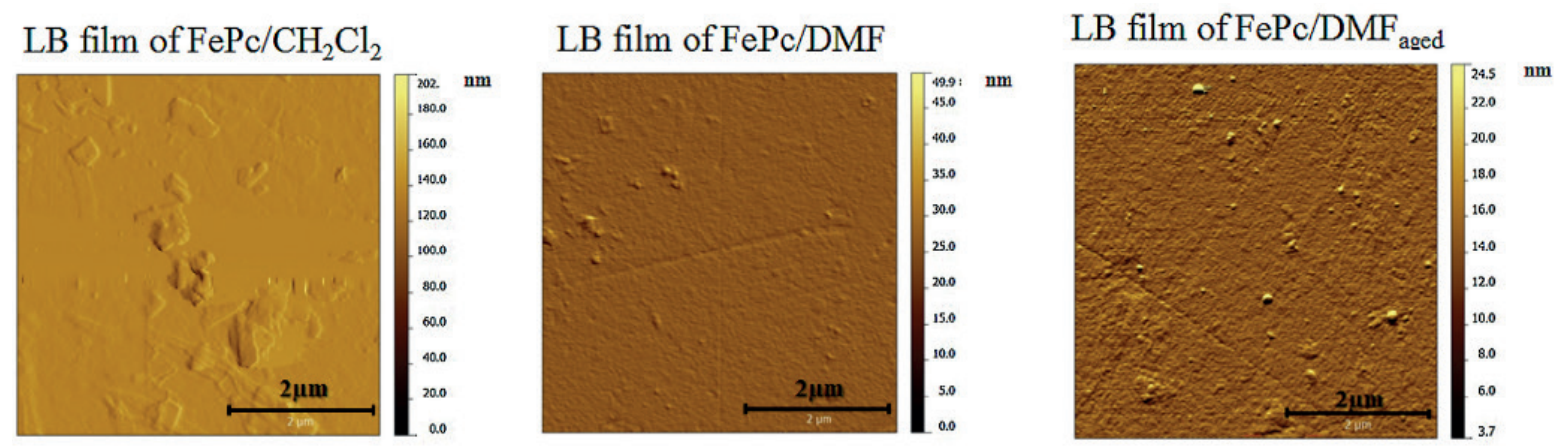

Figure 2 - AFM topographic images for $\mathrm{FePc} / \mathrm{CH}_{2} \mathrm{Cl}_{2}, \mathrm{FePc} / \mathrm{DMF}$ and $\mathrm{FePc} / \mathrm{DMF}$ aged LB films (DMF aged represent the solution of FePc in DMF prepared after one week). Reprinted with permission (Rubira et al. 2017). 

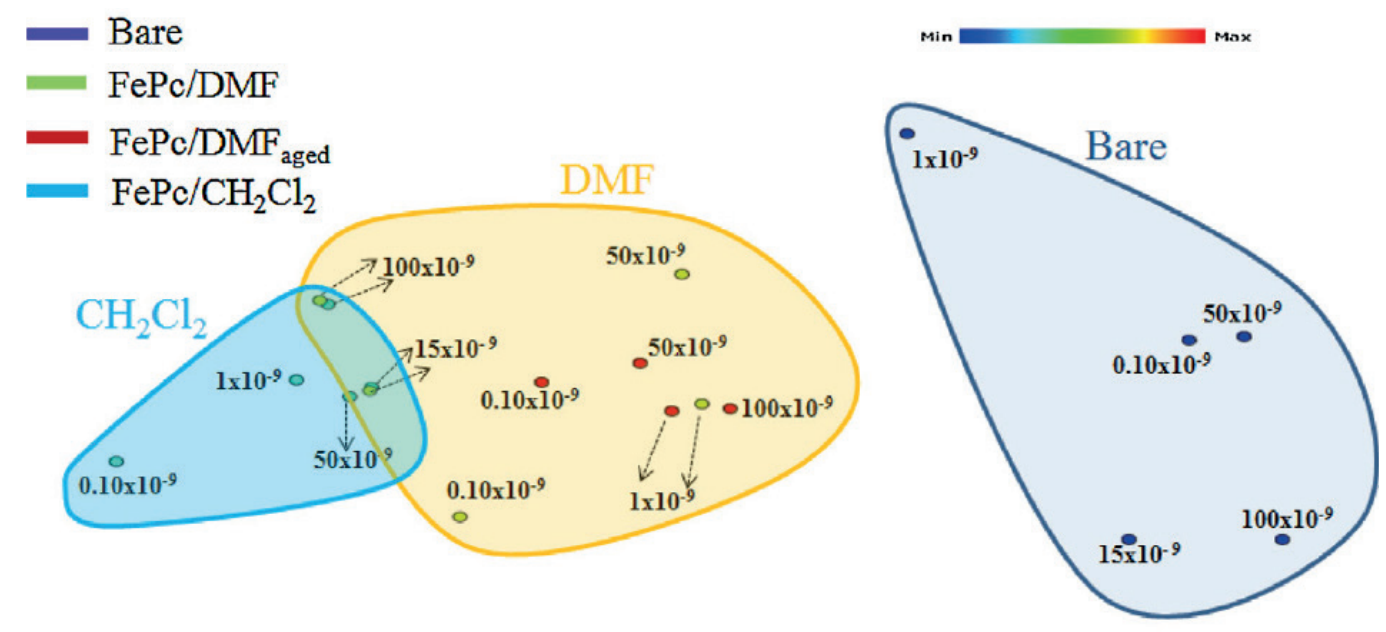

$15 \times 10^{-9}$

Figure 3 - IDMAP projection obtained using capacitance measurements in the presence of atrazine for the FePc films in different solvents.

water interface (Jones et al. 1987). In general, the LB or LS mixed films based on phthalocyanines to electronic devices applications are produced using amphiphilic molecules as matrix and MPc as an electron mediator. The mixture of the amphiphilic molecules in the phthalocyanines Langmuir films is necessary in some cases to improve the flexibility or stability of the monolayers or the affinity to the substrate, which facilities the transfer of the film to the solid substrate forming LB or LS films (Medina-Plaza et al. 2014b, Pavinatto et al. 2011, Valli 2005).

Medina-Plaza et al. (Medina-Plaza et al. 2014b) described the fabrication of codeposited films containing phthalocyanine through the LB technique. These films were composed by an amphiphilic matrix of dimethyldioctadecylammonium bromide (DODAB) and lutetium bisphthalocyanine $\left(\mathrm{LuPc}_{2}\right)$ co-spreading at air/water interface and functionalized gold nanoparticles [(11-mercapto undecyl)tetra(ethylene glycol)] (SAuNPs) at the subphase under the floating films. The incorporation of DODAB on $\mathrm{LuPc}_{2}$ monolayer affects the area per molecule occupied by $\mathrm{LuPc}_{2}$. The equimolar mixture of $\mathrm{LuPc}_{2}: \mathrm{DODAB}$ causes a shift to the bigger area per molecule $\left(240 \AA^{2}\right)$ than $\mathrm{LuPc}_{2}$ only $\left(90 \AA^{2}\right)$, which can be ascribed to the repulsive interaction between $\mathrm{LuPc}_{2}$ and DODAB. Also, the incorporation of SAuNPs promotes displacement of area per molecule only with high $\mathrm{LuPc}_{2}$ proportion. Thus, the insertion of SAuNPs occurs through the conjugation with the $\mathrm{LuPc}_{2}$ molecules (Medina-Plaza et al. 2014b). The BAM and TEM measurements indicate a formation of a stable and homogeneous mixed LB film ( $\mathrm{LuPc}_{2}$ :DODAB) and the incorporation of SAuNPs showed a uniform distribution. Raman spectra from the Langmuir film showed a homogeneous deposition was obtained for the mixture of $\mathrm{LuPc}_{2}$ : DODAB confirming the formation of the LB films with phthalocyanine molecules uniformly distributed. However, the incorporation of SAuNPs promotes an increase of fluorescence making the Raman mapping less defined. The latter, also confirm the changes on supramolecular arrangement caused by the co-deposition on LB films. In addition, the molar proportion of $\mathrm{LuPc}_{2} / \mathrm{DODAB} / \mathrm{SAuNp}$ affects the supramolecular arrangement and also provides a synergistic electrocatalytic effect when applied as hydroquinone sensor using cyclic voltammetry. The increases of $\mathrm{LuPc}_{2}$ and SAuNP 
amount on $\mathrm{LuPc}_{2}$ :DODAB/SAuNP LB films improving the electrocatalysis of hydroquinone detection as well as decreases the limit of detection. The $\mathrm{LuPc}_{2}:$ DODAB/SAuNP assembly with the proportion of $1: 1 / 500$ showed the best sensing results with a linear concentration range from 5.0 $\mathrm{x} 10^{-6}$ to $150 \times 10^{-6} \mathrm{~mol} / \mathrm{L}$ and a limit of detection (4.60 x $\left.10^{-6} \mathrm{~mol} / \mathrm{L}\right)$ (Medina-Plaza et al. 2014b).

The Langmuir techniques also provide a possibility of devices fabrication with a different variety of composition and structure. Recently, Sarkar and Suresh (2018) described LB films of nickel octabutoxy phthalocyanine $\left(\mathrm{NiPc}(\mathrm{OBu})_{8}\right)$ deposited on the HOPG (ordered pyrolytic graphite) substrate and on the HOPG containing a previous LB film of graphite oxide (GO) (Sarkar and Suresh 2018). In that work, the arrangement of MPc films was influenced by the presence of $\mathrm{GO}$ on the substrate surface, assuming a face-on configuration (Sarkar and Suresh 2018). The MPc films exhibit a preferential organization dependent on the deposition technique, substrates and/or substrate composition.

The molecular organization can be determined considering the FTIR spectra combined with the selection rules (Debe 1987), which has been widely applied to determination of molecular organization of MPc films (Alessio et al. 2012, 2014, Furini et al. 2013, Martin et al. 2018, Rubira et al. 2017). In short, this method is based on the scalar product between radiation intensity $(I)$ and electric field (E) as I $\alpha(\vec{\mu} \cdot \vec{E})^{2} I \alpha(\vec{\mu} \cdot \vec{E})^{2}$, being $\mu$ the dipole moment (Debe 1987). Thus, FTIR spectra are collected in transmission and reflection mode, and the relative band intensities ascribed to in-plane, and out-ofplane vibrations are compared. In some cases, comparison with MPc powder dispersed in $\mathrm{KBr}$ pallet or as casting film is also used to characterize the compounds (Furini et al. 2013, Martin et al. 2018).

In LB and LS films from FePc (Martin et al. 2018, Volpati et al. 2008), the band ascribed to $\mathrm{C}-\mathrm{H}$ wagging out-of-plane is dominant in reflection mode, while the band ascribed to $\mathrm{C}-\mathrm{H}$ in-plane deformation are not observed. These changes indicate a tilted organization with the Pc macrocycle oriented between 0 and $45^{\circ}$ with the surface substrate. However, in the LB and LS films from $\mathrm{LuPc}_{2} \mathrm{Cl}_{32}$ similar FTIR spectra in both transmission and reflection mode indicates a random (nonpreferential) molecular organization, as reported by Alessio et al. (2014). These results suggest the MPc structure can influence the molecular organization on LB and LS films. The evaluation of $\mathrm{LB}$ and $\mathrm{LS}$ films of $\mathrm{LuPc}_{2} \mathrm{Cl}_{32}$ as a voltammetric sensor to catechol detection, reported by Alessio et al. (2014). Both LB and LS LuPc ${ }_{2} \mathrm{Cl}_{32}$ films showed an electrocatalytic effect on oxidation potential of catechol in comparison with cast $\mathrm{LuPc}_{2} \mathrm{Cl}_{32}$ film and also with the unmodified electrode. This effect can be attributed to the high number of active sites derivates from the homogeneous layered structure, which was tuned by the deposition techniques. In addition, the arrangement provides a great sensing response to catechol oxidation showing a linear concentration range from $6.0 \times 10^{-5}-5.0$ x $10^{-4} \mathrm{~mol} / \mathrm{L}$ and a limit of detection of $7.5 \times 10^{-5}$ and $8.4 \times 10^{-5} \mathrm{~mol} / \mathrm{L}$ to $\mathrm{LB}$ and $\mathrm{LS} \mathrm{LuPc}_{2} \mathrm{Cl}_{32}$ film, respectively (Alessio et al. 2014).

\section{LAYER-BY-LAYER}

One of the fastest and straightforward film deposition technique available is the Layer-byLayer (LbL), due to its versatility and easy steps of structuring the film. The LbL technique consists fundamentally in the alternated immersion of a substrate in a cationic and anionic solution (Decher 1997, Decher et al. 1992). The deposition occurs due to electrostatic interactions between the previously negatively charged substrate and the positive ions in the first solution. The substrate remains in the solution for a period, and then the excess of material in removed by rising the substrate 
in water. After that, the substrate is immersed in the anionic solution for the same period and then rinsed with water. Such procedure generates a bilayer of positive and negative material, and it can be repeated many times, not exactly in this particular order. LbL technique is applied to MTsPc (tetrasulfonated phthalocyanine) due to solubility in water and the possibility of the assembly film formation (Decher 1997, Decher et al. 1992). A schematic example of LbL deposition using MTsPc is shown in Figure 4. The LbL deposition using MPc in an organic solvent is also reported through specific interactions (Alessio et al. 2010, Fernandes et al. 2011).

Besides, the LbL is a versatile deposition technique, being the film thickness controlled by the number of layers. The growth of the MPc and MTsPc films can be monitored with UV-VIS measurements using a Beer's Law approximation
(Alessio et al. 2017). It because a linear dependence of the absorbance at a specific wavelength (maximum absorption band) with the number of layers or thickness is an indicative the same amount of material is deposited at each layer/thickness. Figure 5 shows examples of linear growth for LbL films.

Also, the LbL technique is an alternative to the development of mimetic biosensors through assembly formation by electrostatic interaction (Alessio et al. 2016). Alessio et al. (2016), describe a structure of LbL films composed by bilayers or trilayers combining $\mathrm{PAH}$ (poly(allylamine) hydrochlorate), as cationic electrolyte, and FeTsPc mixed with DPPG (1,2-dipalmitoyl-sn-3-glycero(phosphor-rac-(1-glycerol)) vesicles, and silver nanoparticles (AgNPs) as anionic electrolyte. The $(\mathrm{PAH} / \mathrm{FeTsPc}+\mathrm{DPPG})_{\mathrm{n}}$ and $(\mathrm{PAH} / \mathrm{FeTsPc}+\mathrm{DPPG} /$ $\mathrm{AgNP})_{\mathrm{n}}$ arranged films showed a homogeneous
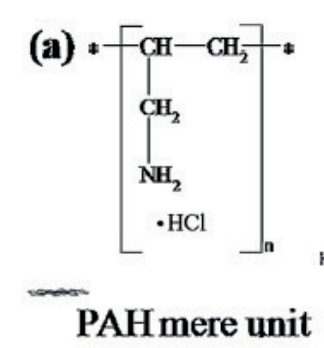

(b)
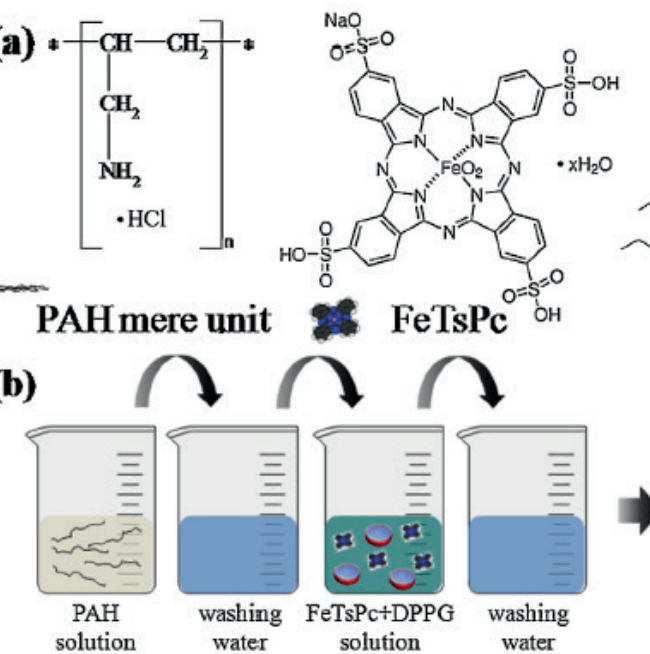

$\mathrm{FeTsPc}{ }_{\mathrm{O}}^{\mathrm{O}=\mathrm{S}}$

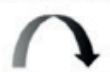

(c)
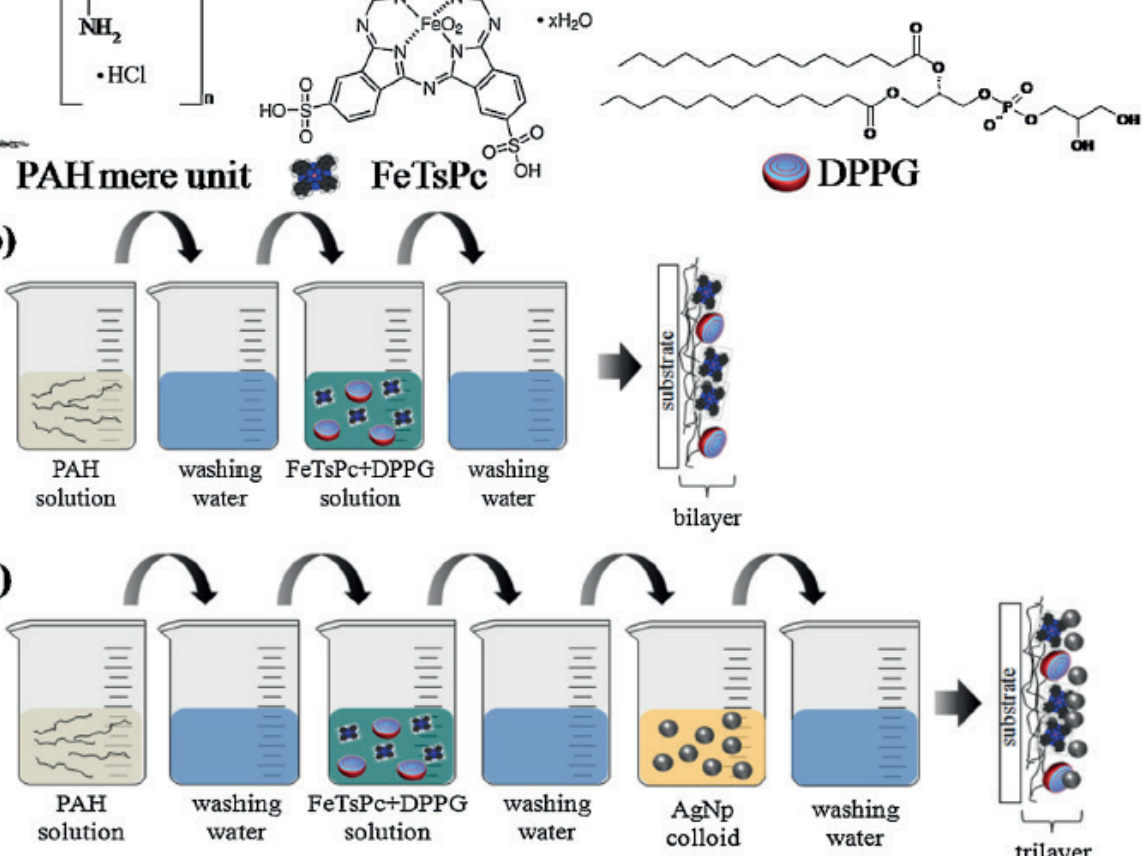

$\mathrm{AgNp}$
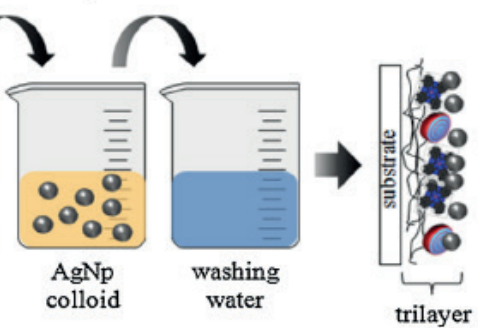

Figure 4 - Schemes of PAH (mere), FeTsPc and DPPG molecular structures as well as the LbL films deposition through the formation of an assembly of bi and tri-layers. Adapted with permission (Alessio et al. 2016). 

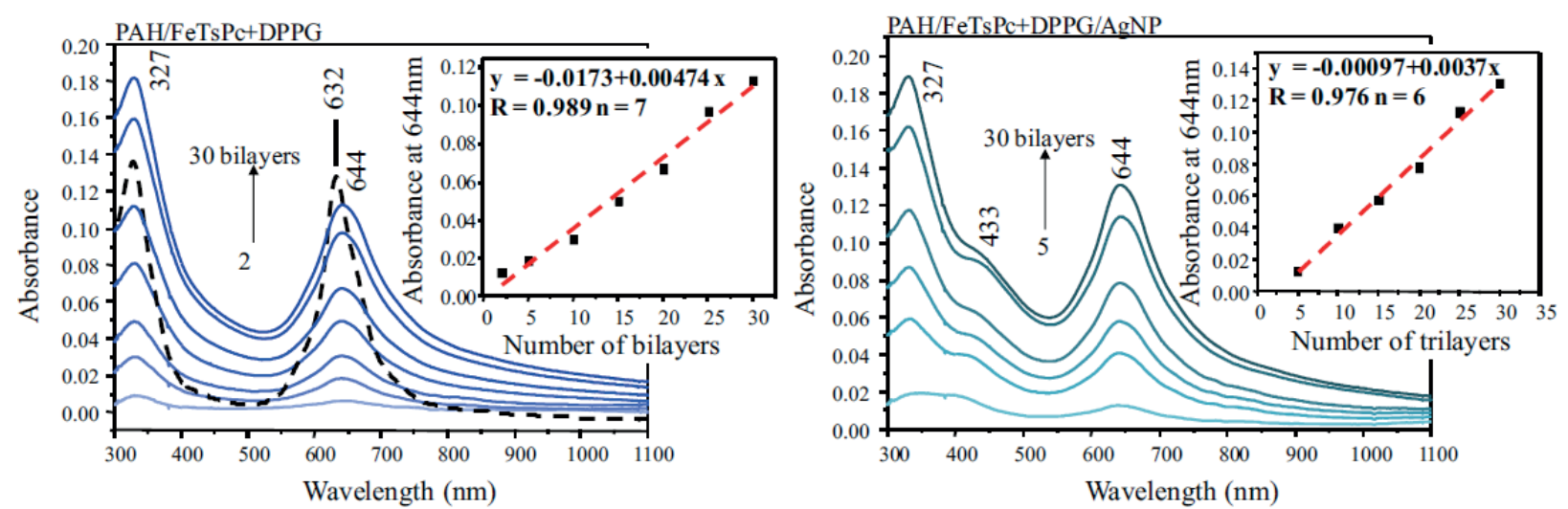

Figure 5 - UV-VIS absorption spectra of (a) PAH/FeTsPc + DPPG LbL films from 2 to 30 bilayers and (b) PAH/FeTsPc + DPPG/ AgNP LbL film from 5 to 30 trilayers. Dashed curve represent the FeTsP + DPPG mixture in aqueous solution. Insets: increases of UV-VIS absorption at $644 \mathrm{~nm}$ as a function of the number of (a') bilayers or (b') trilayers deposited onto a quartz substrate (Alessio et al. 2016).

surface at the micro (Raman mapping) and nanoscales (AFM images), but the presence of AgNp small aggregates are observed. This assembly arrangement can provide an alternative matrix to enzyme immobilization. Indeed, the use of lipid and/or vesicles to the production of $\mathrm{LbL}$ films have opened a new research field to mimetic biosensing applications (Alessio et al. 2011, Aoki et al. 2009).

The sensing properties of $\mathrm{PAH} / \mathrm{FeTsPc}$ can be tuned by the incorporation of anionic phospholipid and metallic nanoparticles, as reported by Alessio et al. (2016). In that study, the electrocatalytic effect for catechol oxidation was higher to PAH/ FeTsPc+DPPG/AgNp LbL arrangement with a linear concentration range from $2 \times 10^{-6}$ to $1.0 \times 10^{-4}$ $\mathrm{mol} / \mathrm{L}$ and limit of detection of $0.87 \times 10^{-6} \mathrm{~mol} / \mathrm{L}$. Also, when applied as an electrochemical device, the presence of $\mathrm{AgNp}$ promotes a direct electron transfer between FeTsPc and electrode surface (Alessio et al. 2016).

The catechol detection was also achieved by electrochemical measurements using PAH/ FeTsPc LbL films (Alessio et al. 2016, Maximino et al. 2016). Maximino et al. (Maximino et al. 2016) described the development of a fast and straightforward sensor using $\mathrm{PAH} / \mathrm{FeTsPc}$ films to catechol detection. This arrangement promotes a linear concentration range from $4.0 \times 10^{-7}$ to $5.0 \mathrm{x}$ $10^{-5} \mathrm{~mol} / \mathrm{L}$ with a limit of detection of $1.76 \times 10^{-7}$ $\mathrm{mol} / \mathrm{L}$. Both works previously cited (Alessio et al. 2016, Maximino et al. 2016), applied the LbL films as a catechol sensor in tea samples, providing results of polyphenol contents in agreement with the Folin-Ciocalteu method (standard method to total polyphenol detection).

The incorporation of MPc onto lipid matrix by using $\mathrm{LbL}$ is an alternative to increases the sensing properties (Alessio et al. 2016, Furini et al. 2013). Furini (Furini et al. 2013) described the effect of NiTsPc concentration on DODAB (dioctadecyldimethylammonium bromide) vesicles formation as well as on the LbL films morphology and arrangement. In this case, differential scanning calorimetry (DSC) showed in the presence of $\mathrm{NiTsPc}$ with a concentration higher than 0.2 $\mathrm{mmol} / \mathrm{L}$ the DODAB vesicles are not formed (Figure 6). The DODAB/NiTsPc LbL films from DODAB dispersion and $0.5 \mathrm{mmol} / \mathrm{L}$ of NiTsPc presented morphology with small clusters ascribed to NiTsPc aggregates, and no vesicles were observed, with DODAB molecules immobilized in the gel state. However, the DODAB/NiTsPc LbL films from DODAB dispersion and $0.05 \mathrm{mmol} / \mathrm{L}$ of 
NiTsPc were more homogeneous with the vesicles polydisperse and immobilized on the subgel state (Furini et al. 2013). The AFM images showed high roughness to LbL films varying from $58.1 \mathrm{~nm}$ for a simple LbL film composition (PEI/NiTsPc) ${ }_{5}$ to $82.2 \mathrm{~nm}$ for more complex LbL composition as (PEI/Na $\left.{ }^{+} \mathrm{MMT} / \mathrm{PEI} / \mathrm{NiTsPc}\right)_{5}$. Also, from Raman mapping, the band at $1560 \mathrm{~cm}^{-1}$ ascribed to $\mathrm{C}=\mathrm{N}$ and $\mathrm{C}=\mathrm{C}$ stretching of isoindole group from NiTsPc present on LbL films, showing a uniform film surface morphology with the presence of isolate aggregates. As proof-of-principle, Furini et al. 2013 (Furini et al. 2013) also evaluated the DODAB/0.5NiTsPc, DODAB/0.05NiTsPc, $\mathrm{PAH} / 0.05 \mathrm{NiTsPc}$, and DODAB/0.05CuTsPc LbL films as a sensor array using impedance spectroscopy (IS) measurements to discriminate dopamine concentrations. The Principal Component Analysis (PCA) obtained from real capacitances in function of dopamine concentration revealed a possibility of discriminated dopamine concentration up to $10^{-6}$ $\mathrm{mol} / \mathrm{L}$.

The incorporation of clay is an alternative to improve the electronic properties of MTsPc in the LbL films through to synergistic effect (de Lucena et al. 2018). Lucena, N.C. et al. (de Lucena et al. 2018) showed the incorporation of montmorillonite clay ( $\left.\mathrm{Na}^{+} \mathrm{MMT}\right)$ and poly(ethylene imine) (PEI) on the NiTsPc LbL films as a quadri-layer assembly $(\mathrm{PEI} / \mathrm{Na}+\mathrm{MMT} / \mathrm{PEI} / \mathrm{NiTs} \mathrm{Pc})_{10}$ and applied to dopamine detection. Using AFM, FTIR and Raman measurements, the authors conclude that the quadrilayer assembly led to a synergistic effect on the roughness. In this work, the sensing results indicate that NiTsPc was responsible for the decrease of dopamine oxidation potential, and also improve the reproducibility, once the LbL arrangement in the absence of NiTsPc showed a poor reproducibility. The quadri-layer assembly (PEI/Na ${ }^{+} \mathrm{MMT} / \mathrm{PEI} /$ $\mathrm{NiTsPc})_{10}$ provides low limit of detection (1.39 $\mathrm{x} 10^{-6} \mathrm{~mol} / \mathrm{L}$ ) in comparison with the LbL films composed only by clay $\left(\mathrm{PEI} / \mathrm{Na}^{+} \mathrm{MMT} /\right)_{10}(2.58 \mathrm{x}$ $\left.10^{-6} \mathrm{~mol} / \mathrm{L}\right)$ or NiTsPc $(\mathrm{PEI} / \mathrm{NiTsPc})_{10}\left(1.71 \times 10^{-6}\right.$ $\mathrm{mol} / \mathrm{L})$. This film was applied as dopamine sensor in urine real samples showing a recovery between $94-111 \%$.

\section{PHYSICAL VAPOR DEPOSITION (PVD)}

Physical vapor deposition (PVD) technique presents many interesting properties, one of them is the high homogeneity of the film produced (Hamburger and Reinders 1917). Such homogenous film is achieved by applying an electric current through a metal boat (Ta boat for example) containing the molecule of interest (which have to be thermally stable) and under vacuum (chamber vacuum $\sim 10^{-6}$ Torr). The current causes the boat temperature to increase up to the interest molecule vaporizing state, which makes it evaporate toward the substrate. Such evaporation can be controlled by a shutter, which only allows the film to be deposited after the evaporation rate achieved uniform values. A crystal quartz balance usually measures the evaporation rate.

In general, PVD films from MPc derivatives showed an excellent supramolecular arrangement to develop technological devices. Among the supramolecular arrangement, the PVD films are known for their high homogeneity, low roughness, and inmostcases exceptional molecularorganization (Alessio et al. 2012, Volpati et al. 2008, Zanfolim et al. 2010). For example, PVD films produce lower roughness of $3.16 \mathrm{~nm}$ for $\mathrm{CoPc}$ film (Alessio et al. 2012) and $5.8 \mathrm{~nm}$ for the $\mathrm{AlClPcF}_{16}$ film (Basova et al. 2013) than LB, LS and LbL films. Besides, depending on the experimental conditions, the LB films can also provide MPc films closed to PVD films (FePc LB film with $5.3 \mathrm{~nm}$, for example, Figure 2) (Rubira et al. 2017).

The 101 spectra collected from the Raman mapping proved no degradation of $\mathrm{CoPc}$ during the thermal evaporation process and also confirm a high homogeneity of the film (Alessio et al. 2012) characteristic of PVD technique. In the case of 


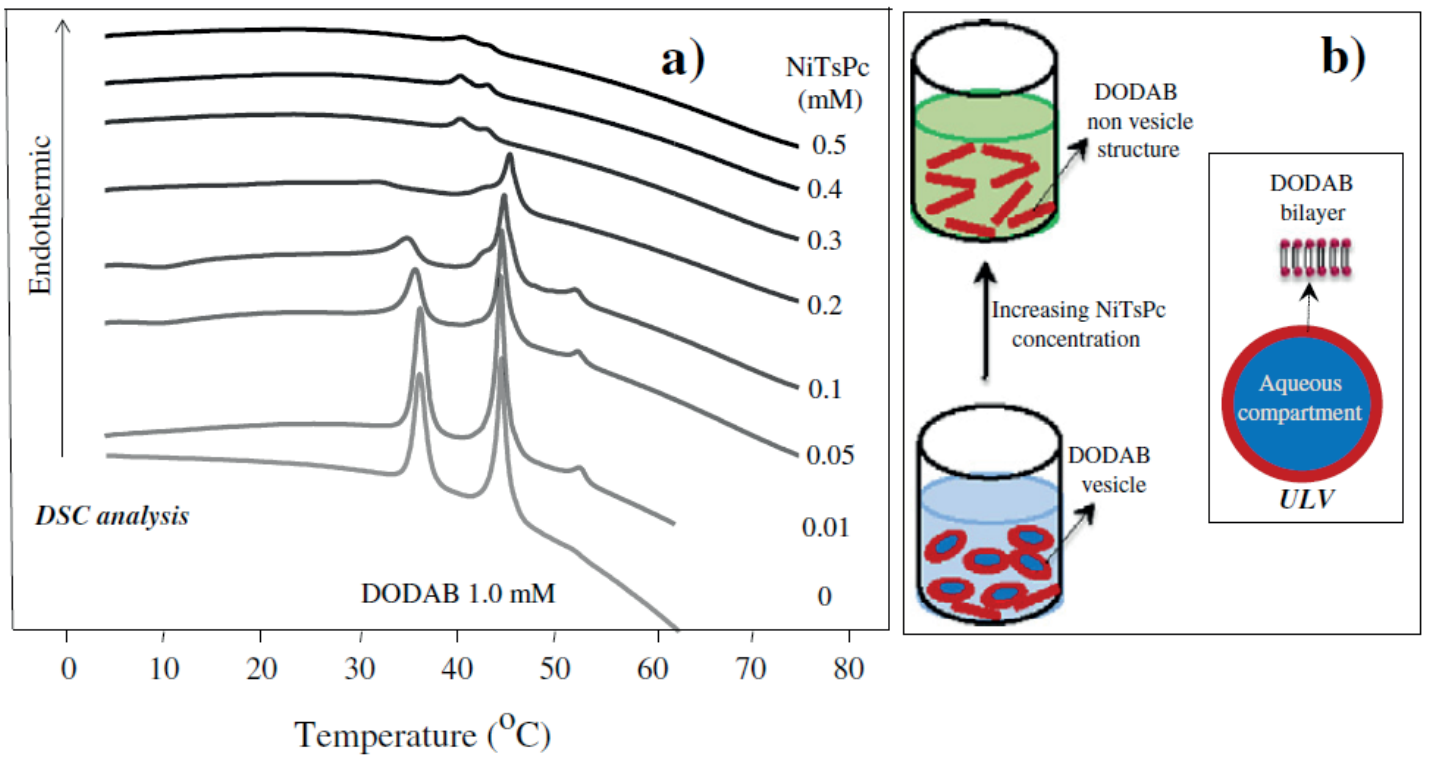

Figure 6 - (a) Heating DSC thermograms for $1.0 \mathrm{nmol} / \mathrm{L}$ DODAB in the absence and presence up to $0.5 \mathrm{~mol} / \mathrm{L}$ NiTsPc. (b) Schematic representation of the possible structures of DODAB in the presence of NiTsPc solution (ULV and non-vesicle structures). Reprinted with permission (Furini et al. 2013).

PVD CoPc films the most intense band, ascribed to pyrrole stretching at $1463 \mathrm{~cm}^{-1}$ was used to Raman mapping (Figure 7).

In relation to molecular organization determined from FTIR measurements (associated with selection rule), as showed the Figure 8 (Alessio et al. 2012, Volpati et al. 2008, Zanfolim et al. 2010), the MPc PVD films from CoPc, ZnPc and $\mathrm{FePc}$, showed an edge-on molecular organization, with the Pc macrocycle tilted between $45^{\circ}$ and $90^{\circ}$ in relation to the substrate surface. In the work of Alessio et al. (2012) such molecular organization allowed the AC conductivity at low frequencies to increased about two orders of magnitude.

Phthalocyanine derivatives with a halogenated substituent $\left(\mathrm{MPc}_{2} \mathrm{X}_{\mathrm{n}}, \mathrm{X}=\mathrm{Cl}, \mathrm{F}\right)$ have also been used for the fabrication of thin films by using PVD technique (Basova et al. 2013, 2018). Basova et al. (2018) reported a PVD film of $\mathrm{VOPcCl}_{16}$ (chlorosubstituted vanadyl phthalocyanine) characterized with polarized Raman, UV-VIS spectroscopy and X-ray diffractions. The results discussed by the authors conclude that the film is disordered and amorphous. However, such an arrangement of $\mathrm{VOPcCl}_{16}$ PVD films promotes charger transfer mobility similar to an organized VOPc film (Del Caño et al. 2005). PVD films of $\mathrm{AlClPcF}_{16}$ (chloroaluminium hexadecafluorophthalocyanine) was also reported by Basova et al. (2013). In opposition to the

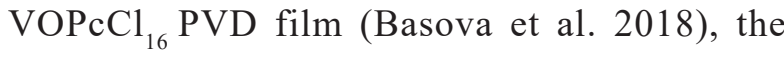
PVD AlClPcF ${ }_{16}$ film showed an arrangement cofacial parallel with molecules oriented vertically to substrate surface (Basova et al. 2013). Both works cited before states that not only the deposition technique but also the structure of MPc (including substituent and metallic center) could affect the supramolecular arrangement.

\section{ELECTRODEPOSITION}

Electrodeposition is a well-known method to deposit thin films into a conductor substrate/ electrode. The technique consists of a controlled accumulation of metal or organometallic compound over a conducting surface using electrolysis from a conventional electrolyte (Paunovic and Schlesinger 2005). Deposition of the material is performed mostly by potential cycling (potentiodynamic 


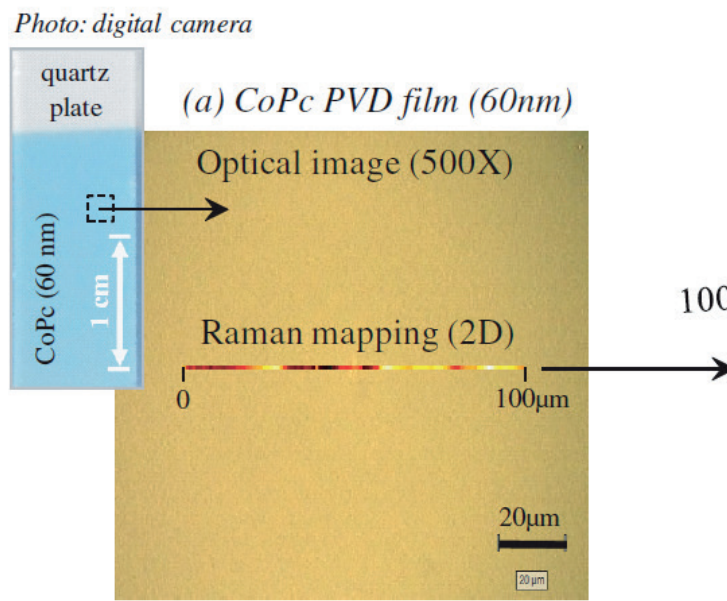

(b) Raman mapping (3D)

Figure 7 - (a) Optical image for a $60 \mathrm{~nm}$ CoPc PVD film and the line $(1 \mu \mathrm{m})$, which represent the region used to record the Raman mapping with a $1 \mu \mathrm{m}$ step (band intensity at $1463 \mathrm{~cm}^{-1}$ ). (b) 101 Raman spectra recorded along mapping line. Reprinted with permission (Alessio et al. 2012).
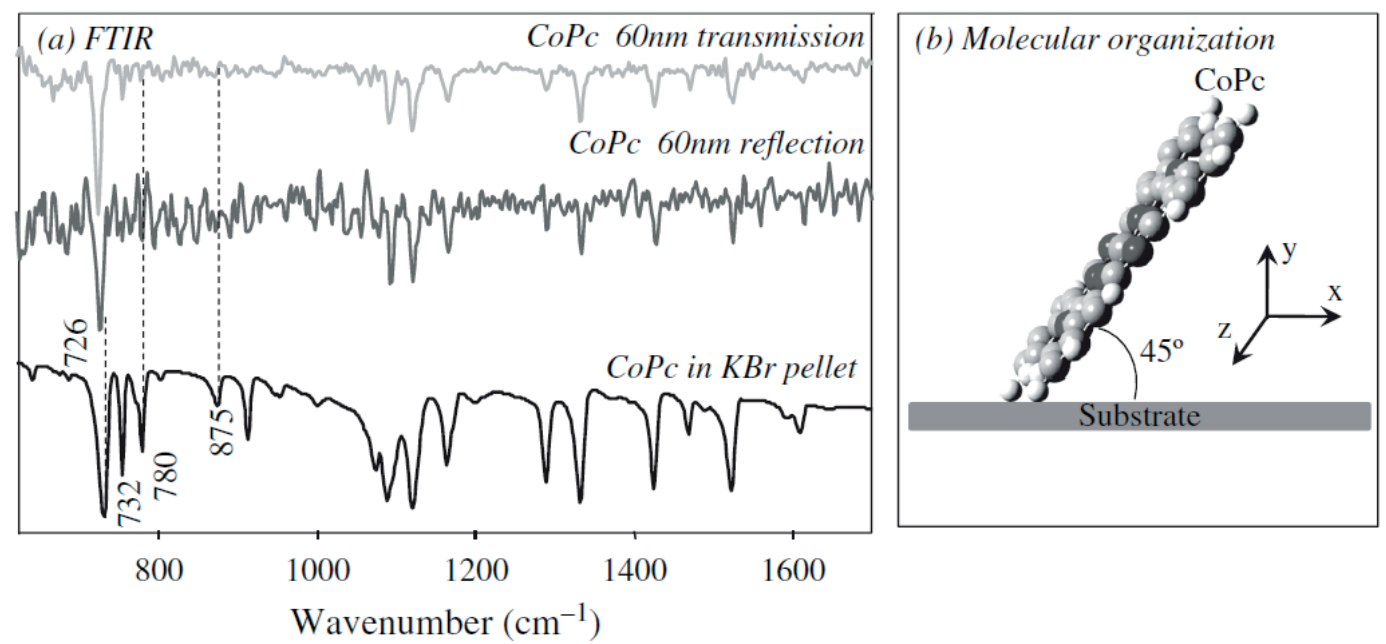

Figure 8 - (a) FTIR spectra recorded from CoPc powder in $\mathrm{KBr}$ pellet and $60 \mathrm{~nm}$ PVD film deposited onto Ge (transmission mode) and Ag mirror (reflection mode), (b) scheme of molecular organization proposed for CoPc in PVD films. Reprinted with permission (Alessio et al. 2012).

electrodeposition) or at a constant potential (potentiostatic electrodeposition) (Martin et al. 2016). The range or fixed potential is applied between the reference and working electrode and the oxidations/reductions in the interface of electrode/ solution are responsible for film formation at the working electrode surface.

The electrodeposition technique using cyclic and constant potential method has been reported as a tool for tuning the MPc films properties
(Chohan et al. 2015, Erdoğmuş et al. 2011, Martin et al. 2016, 2018, Vishwanath and Kandaiah 2016). Electrodeposited FePc films are formed through interaction between the Pc macrocycle rings with the formation of the $\pi-\pi$ aggregates. However, the deposition at a constant applied potential at -1.5 $\mathrm{V}$ promotes the formation of $\left[\mathrm{Fe}^{\mathrm{I}} \mathrm{Pc}^{3-}\right]^{-2}$ species, which increases the negative charge on the $\mathrm{Pc}$ macrocycle. This increase supports an increase in $\pi-\pi$ interaction between the Pc macrocycle rings. 


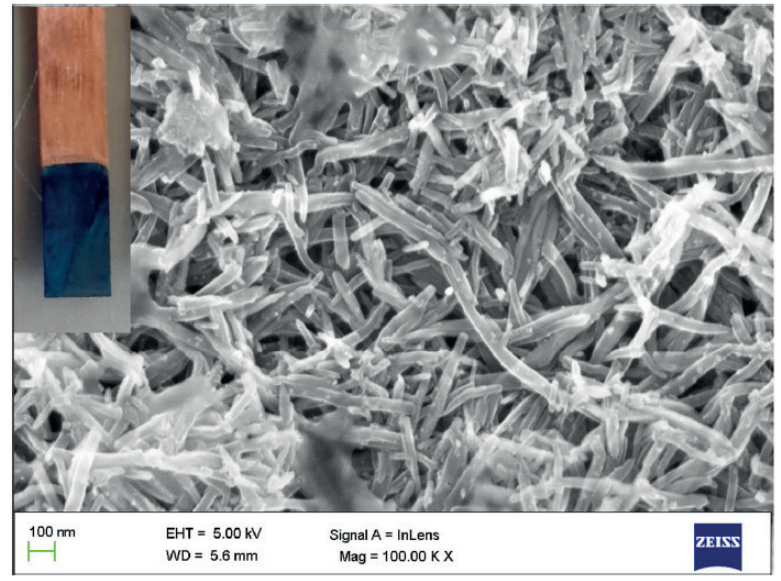

Figure 9 - Scanning electron micrograph of CuPc film on the copper surface showing nanorod-like structures. The inset shows a photograph of electrodeposited $\mathrm{CuPc}$ film on copper electrode. Reprinted with permission (Vishwanath and Kandaiah 2016).

Thus, the formation of $\left[\mathrm{Fe}^{\mathrm{I}} \mathrm{Pc}^{3-}\right]^{-2}$ species is a fundamental step for FePc film formation (Martin et al. 2016). In comparison with LB and LS films, the FePc electrodeposited films are more compact, both aggregation and roughness are lower, and showed a flat-on organization (Martin et al. 2018). The flat-on organization affords a decrease in the energy gap $(\mathrm{Eg})$ to $1.16 \mathrm{eV}$ comparing to the tilted organization $(\mathrm{Eg}=1.30 \mathrm{eV}$ from LS films) (Martin et al. 2018). The electrodeposition of MPc thin films through interaction between the Pc macrocycle rings was also reported by $\mathrm{S}$. Chohan, I. N. Booysen, and A. Mambanda (Chohan et al. 2015). In that work, the films were electrodeposited using cobalt phthalocyanines (CoPcs) tetrasubstituted peripherally by flavone or benzoxazole moieties. The electrodeposition occurred at $-0.9 \mathrm{~V}$ with $\mathrm{Pc}^{2-} / \mathrm{Pc}^{3-}$ and $\mathrm{Co}^{\mathrm{II}} / \mathrm{Co}^{\mathrm{I}}$ reducing and forming aggregates. In both cases, the electrodeposition of FePc (Martin et al. 2018) and CoPc (substituted) (Chohan et al. 2015) promoted a decrease of $Q$ band absorbance, which is associated with the reduction of MPc monomeric species. In the experiments, the applied reduction potential to the electrodeposition is associated with the $d$-orbitals accessible between the HOMO/LUMO gap of Pc ring and consequently with changes in the center metal of MPc (Chohan et al. 2015). The electrodeposited FePc and CoPc films also showed a decreases of oxidation potential of dopamine to dopamine-ortho-quinone close to $0.14 \mathrm{~V}$ in comparison with the glassy carbon bare electrode (GCE), which shows the oxidation potential of dopamine at $0.19 \mathrm{~V}$ (Chohan et al. 2015, Martin et al. 2016).

The co-electrooxidation is a new tool to electrodeposition of MPc thin films on conductor substrates. R. S. Vishwanath and Sakthivel Kandaiah (Vishwanath and Kandaiah 2016) described the electrodeposition of $\mathrm{CuPc}$ thin films from electrooxidation of $\mathrm{Li}_{2} \mathrm{Pc}$ (dilithium phthalocyanine) in an organic solvent using copper electrode. Thus, the $\mathrm{CuPc}$ is electrodeposited at electrode surface from the direct substitution of the metal center from $\mathrm{Li}_{2} \mathrm{Pc}$ to $\mathrm{CuPc}$. These films exhibit a nanorod structure with a predominance of the $\alpha$-phase, and great applicability in photoelectrochemical hydrogen evolution (Figure 9).

\section{ACKNOWLEDGMENTS}

Financial support from Fundação de Amparo à Pesquisa do Estado de São Paulo (FAPESP), Conselho Nacional de Desenvolvimento Científico e Tecnológico (CNPq), and Coordenação de Aperfeiçoamento de Pessoal de Nível Superior (CAPES) is gratefully acknowledged.

\section{AUTHOR CONTRIBUTIONS}

The authors contributed equally to this shortreview.

\section{REFERENCES}

ALESSIO P, AOKI PHB, DE SAJA SAEZ JA, RODRÍGUEZMÉNDEZ ML AND CONSTANTINO CJL. 2011. Combining SERRS and electrochemistry to characterize sensors based on biomembrane mimetic models formed by phospholipids. RSC Adv 1: 211-218.

ALESSIO P, AOKI PHB, FURINI LN, ALIAGA AE AND CONSTANTINO CJL. 2017. 3 - Spectroscopic Techniques for Characterization of Nanomaterials. In: Da Róz AL, Ferreira M, de Lima Leite F and Oliveira ON 
(Eds), Nanocharacterization Techniques, William Andrew Publishing, p. 65-98.

ALESSIO P, APETREI C, RUBIRA RJ, CONSTANTINO CJ, MEDINA-PLAZAL C, DE SAJA JA AND RODRÍGUEZ-MÉNDEZ ML. 2014. Structural and electrochemical properties of lutetium bis-octachlorophthalocyaninatenanostructured films. Application as voltammetric sensors. J Nanosci Nanotechnol 14: 67546763.

ALESSIO PET AL. 2012. Molecular architecture and electrical properties in evaporated films of cobalt phthalocyanine. $\mathrm{J}$ Nanosci Nanotechnol 12: 7010-7020.

ALESSIO P, MARTIN CS, DE SAJA JAAND RODRIGUEZMENDEZ ML. 2016. Mimetic biosensors composed by layer-by-layer films of phospholipid, phthalocyanine and silver nanoparticles to polyphenol detection. Sensors Actuators B. Chem 233: 654-666.

ALESSIO P, RODRÍGUEZ-MÉNDEZ ML, DE SAJA SAEZ JA AND CONSTANTINO CJL. 2010. Iron phthalocyanine in non-aqueous medium forming layerby-layer films: growth mechanism, molecular architecture and applications. Phys Chem Chem Phys 12: 3972-3983.

ANDZELM J, RAWLETT AM, ORLICKI JA, SNYDER JF AND BALDRIDGE KK. 2007. Optical properties of phthalocyanine and naphthalocyanine compounds. J Chem Theory Comput 3: 870-877.

AOKI PHB, VOLPATI D, RIUL A, CAETANO W AND CONSTANTINO CJL. 2009. Layer-by-layer technique as a new approach to produce nanostructured films containing phospholipids as transducers in sensing applications. Langmuir 25: 2331-2338.

BASOVA TV, KISELEV VG, KLYAMER DD AND HASSAN A. 2018. Thin films of chlorosubstituted vanadyl phthalocyanine: charge transport properties and optical spectroscopy study of structure. J Mater Sci Mater Electron 29: 16791-16798.

BASOVA TV, KISELEV VG, SHELUDYAKOVA LA AND YUSHINA IV. 2013. Molecular organization in the thin films of chloroaluminium hexadecafluorophthalocyanine revealed by polarized Raman spectroscopy. Thin Solid Films 548: 650-656.

BLODGETT KB. 1935. Films Built by Depositing Successive Monomolecular Layers on a Solid Surface. J Am Chem Soc 57: 1007-1022.

CAMACHO SA, AOKI P HB, DE ASSIS FF, PIRESA AM AND OLIVEIRA KT. 2014. Supramolecular arrangements of an organometallic forming nanostructured films. Mater Res 17: 1375-1383.

CHOHAN S, BOOYSEN IN AND MAMBANDA A. 2015. Cobalt $\beta$-tetra(3-oxyflavone/2-(2-oxyphenyl) benzoxazole)phthalocyanines and their carbon nanotube conjugates: Formation, characterization and dopamine electrocatalysis. Polyhedron 102: 284-292.

DE LUCENA NC, MIYAZAKI CM, SHIMIZU FM, CONSTANTINO CJL AND FERREIRA M. 2018. Layer-by-layer composite film of nickel phthalocyanine and montmorillonite clay for synergistic effect on electrochemical detection of dopamine. Appl Surf Sci 436: 957-966.

DEBE MK. 1987. Optical probes of organic thin films: Photons-in and photons-out. Prog Surf Sci 24: 1-282.

DECHER G. 1997. Fuzzy nanoassemblies: Toward layered polymeric Multicomposites. Science 277: 1232-1237.

DECHER G, HONG JD AND SCHMITT J. 1992. Buildup of ultrathin multilayer films by a self-assembly process: III. Consecutively alternating adsorption of anionic and cationic polyelectrolytes on charged surfaces. Thin Solid Films 210: 831-835.

DEL CAÑO T, PARRA V, RODRÍGUEZ-MÉNDEZ ML, AROCA RF AND DE SAJA JA. 2005. Characterization of evaporated trivalent and tetravalent phthalocyanines thin films: different degree of organization. Appl Surf Sci 246: 327-333.

ERDOĞMUŞ A, BOOYSEN IN AND NYOKONG T. 2011. Synthesis and electrochemical properties of new tetra substituted cobalt phthalocyanine complexes, and their application in electrode modification for the electrocatalysis of 1-cysteine. Synth Met 161: 241-250.

FERNANDES EGR, BRAZACA LC, RODRÍGUEZMENDEZ ML, DE SAJA JA AND ZUCOLOTTO V. 2011. Immobilization of lutetium bisphthalocyanine in nanostructured biomimetic sensors using the LbL technique for phenol detection. Biosens Bioelectron 26: 4715-4719.

FLEETHAM TB, MUDRICK JP, CAO W, KLIMES K, XUE J AND LI J. 2014. Efficient zinc phthalocyanine/c 60 heterojunction photovoltaic devices employing tetracene anode interfacial layers. ACS Appl Mater Interfaces 6: 7254-7259.

FURINI LN, FEITOSA E, ALESSIO P, SHIMABUKURO MH, RIUL JA AND CONSTANTINO CJL. 2013. Tuning the nanostructure of DODAB/nickel tetrasulfonated phthalocyanine bilayers in LbL films. Mater Sci Eng C 33: 2937-2946.

GAY MARTÍN M, DE SAJA JA, MUÑOZ R AND RODRÍGUEZ-MÉNDEZ ML. 2012. Multisensor system based on bisphthalocyanine nanowires for the detection of antioxidants. Electrochim Acta 68: 88-94.

GOMES TC, OLIVEIRA RF, LOPES EM, KLEM MS, AGOSTINI DLS CONSTANTINO CJL AND ALVES N. 2015. Effects of humidity on the electrical properties of thermal inkjet-printed films of copper tetrasulfonated phthalocyanine (CuTsPc) onto paper substrates. J Mater Sci 50: 2122-2129.

HAKEIM OA, DIAB HA AND ADAMS J. 2015. Preparation and characterization of UV curable-encapsulated phthalocyanine blue pigment. Prog Org Coatings 84: 7078.

HAMBURGER L AND REINDERS W. 1917. Ultramicroscopic investigations of verythin matal-films obtained by evaporation in high vacuum. Proc R Neth Acad Arts Sci (KNAW) 19: 958-979. 
JONES CA, PETTY MC AND ROBERTS GG. 1987. IR studies of pyroelectric Langmuir-Blodgett films. Thin Solid Films 155: 187-195.

LANGMUIR I AND SCHAEFER VJ. 1937. The Effect of Dissolved Salts on Insoluble Monolayers. J Am Chem Soc 59: 2400-2414.

LANGMUIR I AND SCHAEFER VJ. 1938. Activities of Urease and Pepsin Monolayers. J Am Chem Soc 60: 13511360.

MARTIN CS, ALESSIO P, CRESPILHO FN AND CONSTANTINO CJL. 2018. Supramolecular arrangement of iron phthalocyanine in langmuir-schaefer and electrodeposited thin films. J Nanosci Nanotechnol 18: 3206-3217.

MARTIN CS, GOUVEIA-CARIDADE C, CRESPILHO FN, CONSTANTINO CJL AND BRETT CMA. 2016. Iron Phthalocyanine Electrodeposited Films: Characterization and Influence on Dopamine Oxidation. J Phys Chem C 120: 15698-15706.

MAXIMINO MD, MARTIN CS, PAULOVICH F V AND ALESSIO P. 2016. Layer-by-layer thin film of iron phthalocyanine as a simple and fast sensor for polyphenol determination in tea samples. J Food Sci 81: C2344-C2351.

MEDINA-PLAZA C, DE SAJA JA AND RODRIGUEZMENDEZ ML. 2014a. Bioelectronic tongue based on lipidic nanostructured layers containing phenol oxidases and lutetium bisphthalocyanine for the analysis of grapes. Biosen Bioelectron 57: 276-283.

MEDINA-PLAZA C, FURINI LN, CONSTANTINO CJL, DE SAJA JA AND RODRIGUEZ-MENDEZ ML. 2014b. Synergistic electrocatalytic effect of nanostructured mixed films formed by functionalised gold nanoparticles and bisphthalocyanines. Anal Chim Acta 851: 95-102.

PAUNOVIC MAND SCHLESINGER M. 2005. Fundamentals of Electrochemical Deposition: $2^{\text {nd }}$ ed., 373 p.

PAVINATTO FJ, FERNANDES EGR, ALESSIO P, CONSTANTINO CJL, SAJA JA, ZUCOLOTTO V, APETREI C, OLIVEIRA ON AND RODRIGUEZMENDEZ ML. 2011. Optimized architecture for Tyrosinase-containing Langmuir-Blodgett films to detect pyrogallol. J Mater Chem 21: 4995-5003.

PETTY, M. C. 1996. Langmuir-Blodgett films, Cambridge: Cambridge University, p. Xiii-Xiv.

RODRIGUEZ-MÉNDEZ ML, GAY M AND DE SAJA JA. 2009. New insights into sensors based on radical bisphthalocyanines. J Porphyr Phthalocyanines 13: 11591167.

ROY D, DAS NM, SHAKTI N AND GUPTA PS. 2014. Comparative study of optical, structural and electrical properties of zinc phthalocyanine Langmuir-Blodgett thin film on annealing. RSC Adv 4: 42514-42522.
RUBIRA RJG, AOKI PHB, CONSTANTINO CJL AND ALESSIO P. 2017. Supramolecular architectures of iron phthalocyanine Langmuir-Blodgett films: The role played by the solution solvents. Appl Surf Sci 416: 482-491.

SARKAR A AND SURESH KA. 2018. Negative differential resistance in nickel octabutoxy phthalocyanine and nickel octabutoxy phthalocyanine/graphene oxide ultrathin films. J Appl Phys 123: 155501-155507.

SHEEHY B AND DIMAURO LF. 1996. Atomic and molecular dynamics in intense optical fields. Annu Rev Phys Chem 47: 463-494.

TAKEDA A, OKU T, SUZUKI A, AKIYAMA T AND YAMASAKI Y. 2013. Fabrication and characterization of fullerene-based solar cells containing phthalocyanine and naphthalocyanine dimers. Synth Met 177: 48-51.

USOL'TSEVA NV, KAZAK AV, LUK'YANOV IY, SOTSKY VV, SMIRNOVA AI, YUDIN SG, SHAPOSHNIKOV GP AND GALANIN NE. 2014. Influence of molecular structure peculiarities of phthalocyanine derivatives on their supramolecular organization and properties in the bulk and thin films. Phase Transitions 87: 801-813.

VALLI L. 2005. Phthalocyanine-based Langmuir-Blodgett films as chemical sensors. Adv Colloid Interface Sci 116: $13-44$.

VISHWANATH RS AND KANDAIAH S. 2016. Facile electrochemical growth of nanostructured copper phthalocyanine thin film via simultaneous anodic oxidation of copper and dilithium phthalocyanine for photoelectrochemical hydrogen evolution. J Solid State Electrochem 20: 767-773.

VOLPATI D, ALESSIO P, ZANFOLIM AA, STORTI FC, JOB AE, FERREIRA M, RIUL A, OLIVEIRA ON AND CONSTANTINO CJL. 2008. Exploiting distinct molecular architectures of ultrathin films made with iron phthalocyanine for sensing. J Phys Chem B 112: $15275-$ 15282.

WEISS R AND FISCHER J. 2003. Lanthanide phthalocyanine complexes. In: The Porphyrin Handbook. Elsevier, p. 171246.

WÖHRLE D. 1993. Phthalocyanines: Properties and applications. Adv Mater 5: 942-943.

XU H, XIAO J, YAN L, ZHU L AND LIU B. 2016. An electrochemical sensor for selective detection of dopamine based on nickel tetrasulfonated phthalocyanine functionalized nitrogen-doped graphene nanocomposites. J Electroanal Chem 779: 92-98.

ZANFOLIM AA, VOLPATI D, OLIVATI CA, JOB AE AND CONSTANTINO CJL. 2010. Structural and electricoptical properties of zinc phthalocyanine evaporated thin films: temperature and thickness effects. J Phys Chem C 114: $12290-12299$. 